\title{
Application of Minimum Quantity Lubrication for Various Machining Processes - A Mini Review
}

\author{
N. E. H. Zamiruddin'1, N. Rosli1, $2^{*}$ \\ ${ }^{1}$ Faculty of Manufacturing and Mechatronincs Engineering Technology, Universiti Malaysia Pahang, 26600 Pekan Pahang, Malaysia. \\ ${ }^{2}$ Automotive Engineering Centre, Universiti Malaysia Pahang, Universiti Malaysia Pahang, 26600 Pekan, Pahang, Malaysia
}

ABSTRACT - Minimum Quantity Lubrication (MQL) is a great alternative lubricating and cooling environment method that has been widely used to replace the conventional flood coolant which brings drawbacks involving environmental awareness, human's safety and health and manufacturing cost. Taking into account the recent trends, this review paper describes a summary of the research journals reviewed previously $\mathrm{MQL}$ in various machining operations involving milling, turning, drilling and grinding of various types of materials. Most recent papers have described the use of vegetable oils which helps in maintaining the environmentally friendly machining. Also, the aided of nanofluid particles and hybrid environment in MQL application conversed the outstanding efficiency in machining performances as compared to that conventional flood lubrication technology. Briefly, this paper have shown the proficiency of eco-friendly MQL approach in improving the performance of machinability such as reducing the surface roughness of workpiece, increase of tool life and also reducing the cutting temperature that leads to a sustainable machining environment in the future work.
ARTICLE HISTORY

Revised: $28^{\text {th }}$ September 2020

Accepted: $30^{\text {th }}$ September 2020

\section{KEYWORDS}

Minimum Quantity Lubrication,

Lubricant,

Nanofluid,

Surface Roughness,

Tool Life

\section{INTRODUCTION}

Machining operations are of great importance in various industrial sectors such as automotive, oil and gas, electronics, medical and many more since they are widely applied in the manufacture of industrial parts by material removal process. During the metal cutting process, there is direct contact occur between the cutting tool and the workpiece. As a result, the friction occurred give a rise in higher temperature that leads to poor cutting tool life and higher surface roughness at a faster rate. Hence, lubrication is crucial to reduce the existence of heat in high temperature produced during the process [1]. Lubricant oil is extensively used in the machining process due to its capability to lubricate the cutting process, cool down the cutting tool and flush away the chips from the cutting zone [2].

Since then, lubricant oil has been used in the industry to improve machinability in metal cutting process. Traditionally, flood coolant or wet machining has been widely utilized in the machining process with continuous flow of lubricant oil to the workpiece and the cutting tool without considering the amount or quantity needed as long as it is spattering adequate amount of fluid on the workpiece. However, it has been reported that by applying an excessive amount of lubricant oil, the manufacturing cost raised as well as the negative impact on the occupational health and environment hazards [3]. The rising of machining cost has been resulted due to the higher usage of flood coolant in the machining operation. It has been recorded that $17 \%$ from the total machining cost is used for lubrication which include the maintenance and disposal of excessive lubricant oil. On the other hand, persistent exposure to the lubricant oil can cause severe health hazards such as variety of respiratory disorders including occupational asthma, loss of lung function and skin disease such as irritation and skin cancer [4].

Here, Minimum Quantity Lubrication (MQL) has been implemented. MQL is a lubricating method which consists of mixture air pressure and lubricant oil in the form of an aerosol nozzle applied onto the cutting zone. This mist lubrication reduces the friction between cutting tool and the workpiece by forming a thin film of lubricant at the cutting zone with a flow rate range of $30 \mathrm{~mL} / \mathrm{h}$ [5]. Hence, the quantity of oil being used is very little compared to the traditional flood coolant. Conventionally, during the machining process, MQL can be delivered by two ways namely an external and an internal feed systems. External feed systems used a coolant tank to store a coolant and several tubes with their own nozzles that mounted to the tank which can be connected anywhere around the machine or on the machine itself. This system used self-sufficient adjustable air and lubricant flow to ensure considerable amount supply of coolant during the process [6]. Besides, an atomizer is utilized to formulate the aerosol and convey it externally to the machining cutting region as shown in Figure 1. In addition, this external system is more efficient, beneficial and technically suitable for all machining operations. On the other side, in an internal delivery system, cutting fluid can be distributed precisely onto the cutting zone area by mixing up the air and lubricant inside the nozzle and sprayed to the machining zone through a specially fabricated single or dual channels as illustrated in Figure 2. Spindle, tool revolver and tools internal cooling passage are 
operated to distribute the cutting fluid [7]. As compared to external delivery system, dispersion is hardly to achieve as the feed nozzles could not be modified.

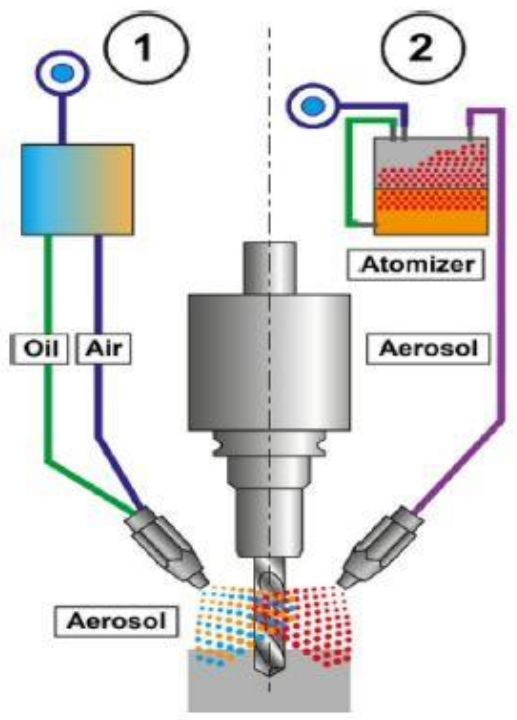

Figure 1. MQL external delivery systems.

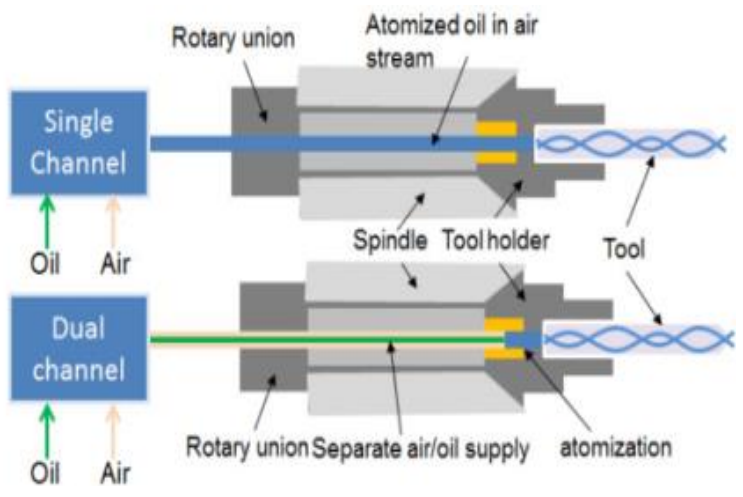

Figure 2. MQL internal delivery systems.

MQL has been developed as a better alternative approach in the machining process as it is proven in reducing the cost consumption [8] and occupational health hazards as well as meeting the environmentally friendly requirements [9]. Lower consumption of lubricant oil during the machining operations leads to reduction of the occupational health hazards, which then simultaneously gives an environmentally friendly effects in the machining process [10]. Furthermore, it also minimizes the environmental impact by significantly decreasing the fluid usage and reducing the manufacturing cost in terms of the excess lubricant oil waste disposal and treatment [11]. Therefore, MQL is proven as a great replacement for conventional flood cooling because of the considerable economic benefits as well as the great performance of machining such as the improvement of cutting tool life and surface finishing.

\section{MQL IN MILLING PROCESS}

Mahmood et. al [12] has analyzed MQL application to improve the performance of machinability on AISI 4140 steel under milling process. By using uncoated carbide tool and varying the machine parameters such as cutting speed, table feed and depth of cut, they have evaluated the cutting force, surface roughness of the workpiece and the flank wear. A slight improvement of surface finish has been achieved with $150 \mathrm{~mL} / \mathrm{h}$ MQL flow rate of VG 68 cut cutting oil under 
varies of cutting speed. Besides that, lower cutting force has also been obtained which contributed to reduction of builtup edge (BUE) formation during the operation. They also concluded that flank wear has also been reduced under MQL application which subsequently increased the tool life. Another researcher has implemented MQL condition to attain better surface roughness compared to flood condition under milling operation of Inconel 718 alloy [13]. By fixing the flow rate of $90 \mathrm{~mL} / \mathrm{h}$ of vegetable-based oil, a better tool life has been improved. This could be clarified due to its better cooling and lubrication performance at the tool-chip and tool-work piece interface. However, while the oil mist of MQL has been proven to enhance the machining efficiency, the tiny droplets of oil mist also easily evaporates thus can reduce the lubrication performance during the machining process. Therefore, the most challenging part in applying the MQL system is to properly supply the lubricant oil to the cutting zone to make sure it provides sufficient lubricating effects for better surface finishing.

Nihat et. al [12] investigated the role of concentration of MQL lubricant oil on the surface roughness in milling 7075T6 aluminium alloy. Boron oil was mixed together with water under ratio of 9:10 and 1:10 to observe the surface quality of the workpiece. They concluded that with ratio of 1:10 concentration, better penetration of cutting fluid into the cutting zone could be performed and thus a better surface quality of the workpiece could be achieved. It was also observed that MQL produced better outcome under lower cutting speed and lower cutting depth [13]. They examined synthetic water soluble type of oil on the mild steel and resulted lower surface roughness with value of $0.95 \mu$ m. Kuan et. al [14] reported the formation of burrs at the edge of workpiece could be reduced by applying MQL in the milling process. Futhermore, with rate of $7.5 \mathrm{~mL} / \mathrm{h} \mathrm{LB}-1$ vegetable oil penetrate onto the cutting region, lower surface roughness could be obtained with range of $0.1 \mu \mathrm{m}$ and $0.2 \mu \mathrm{m}$. Reduction of tool flank wear which leads to the improvement of tool life also could be attained with the application of MQL.

The use of nanoparticles along with MQL were also recommended by many researchers to enhance the performance of machinability. Alper et. al [15] has added $1 \mathrm{wt} \%$ of $\mathrm{MoS}_{2}$ particles into the Eraoil 2000 commercial vegetable oil to examine the tool wear and surface roughness of AISI 420 martensitic stainless steel in milling operation. From the results, it was found out that the tool wear has been reduced by $16.8 \%$ and $19.9 \%$ with MQL nano $\mathrm{MoS}_{2}$ particles compared to MQL condition under $20 \mathrm{~mL} / \mathrm{h}$ and $40 \mathrm{~mL} / \mathrm{h}$ respectively. This could be explained due to lubrication effects of nano $\mathrm{MoS}_{2}$ particles that reduced the friction in the cutting zone area. Other than that, surface roughness was achieved as lowest as $0.8644 \mu \mathrm{m}$ in MQL nanofluid condition at $40 \mathrm{~mL} / \mathrm{h}$ flow rate as a result of more mixture of air pressure and lubricant oil penetrating the cutting zone. Recent report [16] revealed that the addition of $\mathrm{MWCNT}_{\mathrm{s}}$ nanofluid particles into the MQL condition could improve the performance of flank wear and surface finishing of Inconel 718 under milling process. The presence of nanofluid particles enhanced the cooling and lubrication properties which improved lubrication and wetting properties of the rake and flank regions.

Another series of experiments using MQL technology were utilized by adding hybrid nanoparticle water basedlubricants into the MQL solution [17]. They used graphene oxide (GO) and silicone dioxide $\left(\mathrm{SiO}_{2}\right)$ hybrid nanoparticles to surpass the tool wear progression and surface roughness of AISI 304 stainless steel. As a result of these experiments, it showed that $\mathrm{GO}: \mathrm{SiO}_{2}$ hybrid nanoparticles water-based MQL reduced the surface roughness of the workpiece compared to MQL condition. Besides, they also concluded that a greater tool life could be obtained when $\mathrm{GO}_{\mathrm{SiO}} \mathrm{S}_{2}$ were added into the MQL lubricant oil. Alborz et.al [18] conducted milling operations of Inconel 718 alloy by using MQL, cryogenic and hybrid cryogenic environments. Hybrid cryogenic environment was found to be the best condition in achieving higher tool life with $50 \%$ better than MQL and $33 \%$ better than cryogenic environment. The heat from the cutting zone area has been reduced constructively due to the presence of liquid nitrogen (LN2) in hybrid environment thus tool wear progression has been decreased. In addition, surface roughness of the workpiece was resulted as low as $0.4 \mu \mathrm{m}$ in hybrid MQL environment.

Kyung et. al [19] machined Ti-6Al-4V titanium alloy using both MQL and nanofluid MQL technique, where a mist of rapeseed vegetable oil and addition of exfoliated graphite nano-platelets $(\mathrm{xGnP})$ particles were sprayed into the cutting zone to evaluate the tool wear progression of uncoated carbide insert. They concluded that nanofluid MQL technique showed the greatest performance of tool wear as the smallest flank wear was $0.153 \mathrm{~mm}$ at flow rate of $9 \mathrm{ml} / \mathrm{min}$. The existence of $\mathrm{xGnP}$ particles into the MQL lubricant played the crucial aspect to diminish the friction occur between the tool and the workpiece hence improve the quality of surface finishing and tool life.

\section{MQL IN TURNING PROCESS}

The great performance of MQL in machining operations has also been explosively justified by its efficiency in turning process. Yazid et. al [22] has proven MQL to be a surpass alternative lubricating method being applied onto the cutting zone with a flow rate range of $50 \mathrm{~mL} / \mathrm{h}$ to ensure the superior penetration with very little amount of lubricant oil. They have successfully implemented MQL in reducing the surface roughness under turning process of Inconel 718 alloy. Sunil et. al [23] utilized the MQL application to improve the surface quality of Inconel 718 alloy using PVD TiAlN coated finegrained high cobalt carbide as the cutting tool. They also evaluated the effect of varying cutting parameters on the surface quality performance of the workpiece material. The best surface roughness was obtained at $0.91 \mu \mathrm{m}$ with medium cutting speed and feed rate. Futhermore, a slight improvement of $12 \%$ to $17 \%$ smoother surface finish has been achieved with the utilization of MQL.

Patole et. al [24] has conducted MQL turning experiments on AISI 4340 alloy steel by adjusting certain machining parameters such as cutting speed, feed rate and cutting depth. Factors such as surface roughness and cutting force were taken as the response parameters for the experiments. From the analysis, it can be concluded that MQL gave better 
outcomes in terms of surface roughness and the cutting force under lower optimal cutting parameters with the lowest feed rate at $0.04 \mathrm{~m} / \mathrm{min}$, cutting speed at $75 \mathrm{~m} / \mathrm{min}$ and cutting depth at $1 \mathrm{~mm}$. Apart from that, Rabesh et. al [25] examined MQL in their research work by adding graphene nanoplatelets $(\mathrm{GnP})$ as nanofluid particles into the lubricant oil. AISI 304 steel was chosen as their work material and uncoated cemented tungsten carbide as the cutting tool. A minimum value of cutting temperature could be recorded due to the high concentration of graphene nanoparticles in the MQL base fluid. Other than that, the reduction of surface roughness could also be recorded in their research work.

There were also studies involve nanofluid particles being added into the MQL lubricant oil to enhance the performance of turning process. Previous work by Musavi et. al [26] has added nano-silicon oxide $\left(\mathrm{SiO}_{2}\right)$ and nano-copper oxide (CuO) as nanofluid particles to improve the surface roughness of A286 superalloy under turning operation. Crucial improvement has been observed to the surface roughness of the workpiece with slightly improvement of $23 \%$ and $26.5 \%$ under $\mathrm{MQL}+\mathrm{SiO}_{2}$ and $\mathrm{MQL}+\mathrm{CuO}$ respectively. Better surface quality could be achieved when $\mathrm{CuO}$ was chosen compared to $\mathrm{SiO}_{2}$ because better lubrication property occurred due to the spherical morphology of copper-oxide nanoparticles. Shuang et. al [27] conducted an investigation on the performance and mechanism of graphene oxide (GO) nano fluids in turning Ti-6Al-4V titanium alloy. The results showed that less scratch of surface topography has been formed on the workpiece hence $27.51 \%$ lesser of surface roughness has been recorded compared to conventional flood cooling condition. Nonetheless,to increase the penetration capability of the oil mist through the cutting zone, sufficient amount of oil utilized by MQL machining operation must be fundamentally considered to analyze the lubricating mechanism onto the cutting zone.This is to ensure that a proper selection of process parameters under MQL has been properly taken care of to provide good surface roughness, reduce the tool wear and maintaining the cutting forces during the machining.

A study of parametric optimization of MQL in turning of AISI 4340 alloy steel using nanofluid has been reported to examine the surface roughness by varying the flow rate, pressure and type of nanofluids particles using the ANOVA and Taguchi method of analysis [28]. From the analysis, cutting fluid (nanofluid) was found to be the most contributing factor followed by flow rate in producing lower surface roughness under MQL nanofluid application. In addition, there has been a great improvement on surface roughness of AISI 431 stainless steel under turning operation when boric acid powder was added as nanofluid particles, as reported by Mahadi et. al [29]. The surface roughness has been improved by $7.21 \%$ with boric acid aided into palm kernel vegetable oil as the properties of boric acid that has lower coefficient of friction. Also, the transfer of heat at the cutting zone has been increased due to the higher thermal conductivity of boric acid powder. Therefore, the cutting temperature of the operation has been reduced that leads to a better tool life progression.

Cagri et. al [30] has revealed that the addition of hexagonal boron nitride ( $\mathrm{hBn}$ ) nanoparticles into the MQL lubricant oil could enhanced the surface quality of nickel-based Inconel 625 and also developed a better tool life of PVD TiAlNTiN coated cemented carbide cutting tool. $0.5 \mathrm{vol} \%$ and $1.0 \mathrm{vol} \%$ of hBn nanoparticles were experimented in this condition to analyze the parameters evaluated. It could be seen that the lowest tool life could be obtained with 1.0 vol\% $\mathrm{hBn}$ nano MQL. This is due to the fact that the cutting oil viscosity has been increased by the excess of hBn concentration. Thus, the lubrication efficiency has been reduced as the cutting oil cannot interfere with the tool-chip interface. Therefore, a lower ratio of $\mathrm{hBn}$ concentration nanoparticles could be used instead. On the other hand, the best surface quality of the workpiece could be achieved in $0.5 \mathrm{vol} \%$ of $\mathrm{hBn}$ nanoparticles because the cutting fluid could penetrated better into the cutting zone. Moreover, Anuj et. al [31] has suggested hybrid nano-MQL cutting fluid as a better alternative of lubrication method in turning AISI 304 steel. They have proved that the lowest values of cutting force and surface roughness with $110.20 \mathrm{~N}$ and $0.953 \mu \mathrm{m}$ could be achieved respectively.

\section{MQL IN DRILLING PROCESS}

In drilling process, the accretion of heat commonly occurred at the final step of machining due to the formation of build up edge as the cutting tool furthered deeper into the workpiece and thus affected the surface quality at the exit hole. However, the utilization of MQL minimized the burr formation at the exit hole surface for the drilled holes due to enhanced heat transfer of the cutting fluids into the contact zone [32]. Besides, build up edge formation at the cutting edge and tool wear performance also has been improved that leads to produce good surface quality. Further study on the formation of burr in exit hole surface was also done by Rahim et. al [33] where they found that the burr formation and burr height has greatly decreased due to the reduction of torque and thrust force of drilling occur in applying MQL technique. Tool wear rate also has been improved by using palm oil as the an alternative to traditional lubricant oil in MQL. Different types of natural biodegradable provides different viscosity which resulted in cooling effect and surface finishing of the workpiece. It has been proved that in high speed machining, low viscosity oils provide better coolant effect and better surface roughness with longer tool life [34]. Similar findings were also found that low viscosity oils can enhance the tool life performance with lower cutting force and cutting temperature during the machining process [35]. This matter can be clarified if the behaviour of MQL lubricant oil during the machining process is properly observed.

There is no doubt that the MQL machining parameter in drilling process also plays a great role in enhancing the lubricating effect on the surface finish quality of drilled material. High flow rate and high pressure were recommended by Nithin et. al [36] for better lubrication penetrated onto the cutting zone area. Other than that, MQL environment has proven to show significant effect on the thrust force compared to flood cooling and dry machining environment which decreased the burr formation at the drilled hole surface. A similar finding has also been studied by Beatriz et. al [37] where they varying the machining parameters in MQL drilling operation of magnesium alloy. The factors selected are feed rate and cutting speed and it resulted that the most improved surface roughness has been obtained at high cutting speed with lower feed rate. 
Basically, the cutting tool condition affected on the surface roughness of the workpiece. This has been reported by Ahmad et. al [38] where they investigated the effect of cutting tool coating during MQL drilling of austenitic stainless steel using refined palm olein oil as the lubricant oil. Two types of tool coating i.e. TiAlN and TiSiN tungsten carbide drill were used in their experiment. To conclude, drilling of MQL using TiSiN coated carbide tool produced better result of the tool life. Meanwhile, the best result of surface roughness of the workpiece has been recorded by TiAlN coated tool. Also, the tool condition (new or worn tool) could be another factor that affects the surface roughness of the machined surface. Sandip et. al [39] studied the effect of MQL mist spray cooling on drilling of Ti-6Al-4V titanium alloy using ester oil as cutting fluid. They indicated that the MQL cooling condition has improved the flank wear better than wet machining condition. In addition, an improvement of $66 \%$ on tool life has also been recorded during the investigation.

Few intellectuals [40] pointed out that the application of nanofluid MQL could also help to improve the work quality of the drilling process. Carbon nano tube (CNT) nanoparticles was added into the vegetable based oil to be used during drilling of AISI 1045 carbon steel. Reduction of thrust force and torque could be showed when nanofluid MQL was utilized. Hence, machining power consumption also has been reduced which leads to sustainable drilling environment. Jung et. al [41] analyzed the development of nano-diamond particles that acts as the nanofluid into the paraffin oil and vegetable oil. They reported that the magnitudes of drilling torques and thrust force has significantly reduced due to the application of MQL nanofluids. Besides, they also differentiated the concentration of the nano-diamond particles into the two types of lubricant oil. As a result, the reduction of thrust force and torque performed more effective with 1 vol\% of nano-diamond particles in paraffin oil while for vegetable oil cases, the result was recorded better with 2 vol\% of nanodiamond particles. Last but not least, due to the enhanced lubrication and reduced chip adhesion by the MQL nanofluid technique, the remaining chips inside the drilled holes and burrs formation around the workpiece surface has been eliminated. Therefore, the quality of the drilled holes has been enhanced.

Sukhpal et. al [42] machined the aluminium 6063 alloy using the nanofluid MQL technique by added nano aluminium oxide $\left(\mathrm{Al}_{2} \mathrm{O}_{3}\right)$ into the refined soya bean oil. They observed that nanofluid MQL using nano particles exhibited better results compared to conventional flood cooling, dry and pure MQL environment in terms of machining force, surface roughness and tool wear. In this investigation, they have found out that the thrust forces and drilling torques have been reduced in both pure MQL and nanofluid MQL condition. However, it is resulted that nanofluid MQL environment is much more effective because the presence of $\mathrm{Al}_{2} \mathrm{O}_{3}$ nanoparticles has produced a thin protective layer between the toolworkpiece interfaces which leads to improve the machining performance by reducing the thrust force. Other than that, the lowest surface roughness of $0.84 \mu \mathrm{m}$ with a higher tool life also has been achieved in nanofluid MQL condition. During the drilling operation, burrs and chips formation has been eliminated effectively as the nanoparticles helped to prevent chips from being welded to the drill tool.

Previous work conducted by Rosnan et. al [43] found that implementation of MQL nanofluid with coated carbide drills has outperformed the tool life progression compared with uncoated carbide drills. In this study, an improvement of $88 \%$ in tool life has been obtained by the TiAlN coated tungsten carbide better than uncoated drills in MQL nanofluid condition. Apart from that, the polishing or rolling effects of the nanoparticles between two contact surface has been aided by the presence of nanoparticles in the base lubricant oils. Therefore, the coefficient friction between the cutting tool and the workpiece has been deducted which leads to improvement of the surface quality of the machined area.

\section{MQL IN GRINDING PROCESS}

Basically, greater heat generation in grinding zone causes the penetration ability of cutting fluids into the cutting zone becomes fewer and thus gives effects on poor machining performance. Therefore, Tawakoli et. al [40] has presented the ability of MQL in increasing wheel life and improving the good surface quality of the ground parts in grinding machining. This can be explained by the efficiency of the lubrication and cooling effects of the abrasive grains around the grinding wheel which allows a better slipping of the chips at the tool surface. Hence, better surface finish of the workpiece can be achieved. Moreover, slipping of the grain at the workpiece-tool interface has been enhanced due to the presence of the MQL lubricant oil that reduced the tangential grinding forces. Rabiei et. al [41] also investigated the competency of lubricant oil to be penetrated into the cutting zone with MQL method in the grinding process. They concluded that a better cutting conditions has been performed with lower friction coefficient due to the adequate amount of lubricant oil being supplied onto the contact zone with high pressure. Lower power consumption in grinding also has been achieved as well as lower surface roughness compared to flood cooling method.

Due to immense power requirements and high temperatures during the operation, abrasive material removal methods can be very challenging. Thus, Barczak et. al [42] implemented MQL lubricating and cooling method to ensure the temperature levels do not exceeded. They found out that low friction conditions under MQL environment has influenced the reduction in cutting temperatures during grinding process and hence a reasonable specific material removal rate has been obtained. In addition, the surface quality of the workpiece has been improved under MQL environment. On the other hand, Mohsen et. al [43] conducted a test on different types of natural biodegradable oil classified as mineral oil, hydrocracked oil, synthetic oil and vegetable palm kernel oil to observe the effect on the specific energy and surface finish of the workpiece. Through the medium of grinding operation of $\mathrm{Al}_{2} \mathrm{O}_{3}$ ceramics, they have revealed that specific energy has been lowered with the application of synthetic oil. Meanwhile, better surface finish quality of workpiece has been shown with hydrocracked based oil. To conclude, synthetic oil and hydrocracked oil were analyzed as the best performance of MQL cutting fluid due to the high thermal stability of the oils. 
There is a huge scope of studying the lubricant oil behavior effects by varying the MQL nozzle distance from the cutting zone, as being reported by Hadad [44]. The critical issue on the distance of MQL oil mist has been discussed to enhance the oil mist penetration into the contact zone. In this scope, his work has shows that the lubrication effects decreased with decreasing MQL nozzle distance. Besides that, too small of oil droplets size were not beneficial in producing better lubrication effects because smaller size of oil droplets tends to evaporate faster than the larger size of oil droplets. MQL is also proven in minimized the environmental impacts by significantly lessening fluid usage and get rid of the need for coolant treatment and disposal, as being proven by the work of Esmaeili et. al [45]. Therefore, they found out that overall manufacturing production costs could been reduced with MQL implementation.

Xianpeng et. al [46] investigated the lubricating properties of nanofluid particles to evaluate the effects on machining performance of Inconel 718 alloy under grinding process. In this investigation, different particles sizes of $\mathrm{Al}_{2} \mathrm{O}_{3}$ and $\mathrm{SiC}$ were mixed at the concentration of $2 \%$ volume with vegetable based oil. They concluded that surface roughness of the workpiece was greatly affected by the size of $\mathrm{Al}_{2} \mathrm{O}_{3}$ as better result of surface roughness could be achieved with smaller sizes of the nanoparticles. Other than that, the best grinding effect also could be performed when $\mathrm{Al}_{2} \mathrm{O}_{3}$ mixed with $\mathrm{SiC}$ in the ratio of 30:70. A similar finding has also been reported by Yanbin et. al [47] where they used molybdenum disulphide $\left(\mathrm{MoS}_{2}\right)$, carbon nanotubes (CNTs) nanofluid MQL technique in grinding operation and it resulted that the surface roughness of the workpiece has been decreased as mass fraction of nanoparticles decreased. This phenomenon has occurred due to the viscosity effects of the nanofluid particles.

Previous work by Wang et. al [48] has successfully implemented the MQL lubricating method by the addition of few types nanoparticles into the palm oil. By grinding nickel alloy GH4169, the grinding force has been reduced in the application of nanofluid MQL and hence enhanced the surface finish of the workpiece better compared to pure lubricant oil. Ming et. al [49] has analyzed the influence of graphene ( $\mathrm{GnP}$ ) nanoparticles in the performance of grinding force and the surface roughness of TC4 titanium alloy. They found out that the grinding force and grinding temperature has been minimized with the concentration of $\mathrm{GnP}$ is $0.1 \mathrm{wt} \%$. This can be explained because moderate amount of GnP helps to strengthen the cooling performances of the formed oil films on the contact area that leads to reduction of grinding heat. Other than that, grinding burn and large groove during the machining also has been decreased and better surface finish of the workpiece has been obtained.

\section{CONCLUSION}

In summary, minimum quantity lubrication (MQL) have shown a great performance in various machining operations involving milling, turning, drilling and grinding for various type of materials. A bunch of researchers have reported to show a noticeable improvement in performance with MQL machining compared to conventional flood cooling and dry machining method. This technology has contributed to enhance the machinability characteristics by improving the surface quality of workpiece, providing a higher quality of tool life as well as reducing the cutting temperature. Besides, the use of non-biodegradable oils as the MQL lubricant make this technique is an environmentally friendly machining process. Hence, because of the considerable economic benefits and also it has been shown to result in better machinability characteristics, it can be concluded that MQL is proven as a great replacement for conventional cooling systems in the future machining operations. However, the behaviour of MQL lubricant oil to prove the performance of the MQL machining process is highly important to be observed. Among the main factors that affects the performance of MQL machining process, lubricant oil droplets is the most important to be properly studied since the amount being applied is very little compared to flood cooling. This matter can be clarified if the behaviour of MQL lubricant oil during the machining process is properly observed. To date, this study is still scarce due to the reason that the natural flow of the lubricant oil cannot be distrupted during the machining operation. Therefore, the authors recommended further investigation is needed to purely study the behaviour of MQL lubricant oil so the effects of MQL system parameter on the machining performance can be clarified in details through the observation on the MQL lubricant behaviour.

\section{ACKNOWLEDGEMENT}

This paper was supported by UMP Research \& Innovation Department (Grant no. RDU1803129) and Ministry of Higher Education Malaysia (Grant no. RDU190124).

\section{REFERENCES}

[1] E. A. Rahim and H. Dorairaju, "Evaluation of mist flow characteristic and performance in Minimum Quantity Lubrication (MQL) machining," Meas. J. Int. Meas. Confed., vol. 123, no. December 2017, pp. 213-225, 2018.

[2] J. Kouam, V. Songmene, M. Balazinski, and P. Hendrick, "Effects of minimum quantity lubricating ( MQL ) conditions on machining of 7075-T6 aluminum alloy," pp. 1325-1334, 2015.

[3] W. A. Khan, N. M. Hoang, B. Tai, and W. N. P. Hung, "Through-tool minimum quantity lubrication and effect on machinability," J. Manuf. Process., vol. 34, no. November 2017, pp. 750-757, 2018.

[4] J. Sharma and B. Singh, "Investigation of effects of dry and near dry machining on AISI D2 steel using vegetable oil," $J$. Clean. Prod., vol. 66, pp. 619-623, 2014.

[5] V. S. Sharma, G. Singh, and K. Sørby, "A Review on Minimum Quantity Lubrication for Machining Processes Machining 
Processes," vol. 6914, 2015.

[6] K. A. Osman, Ö. Ünver, and Ş. Ulvi, “Application of minimum quantity lubrication techniques in machining process of titanium alloy for sustainability: a review," pp. 2311-2332, 2019.

[7] B. Sen, M. Mia, G. M. Krolczyk, U. K. Mandal, and S. P. Mondal, Eco-Friendly Cutting Fluids in Minimum Quantity Lubrication Assisted Machining: A Review on the Perception of Sustainable Manufacturing, no. 0123456789. Korean Society for Precision Engineering, 2019.

[8] A. Duchosal, S. Werda, R. Serra, C. Courbon, and R. Leroy, "Experimental method to analyze the oil mist impingement over an insert used in MQL milling process," Meas. J. Int. Meas. Confed., vol. 86, pp. 283-292, 2016.

[9] E. Vazquez, J. Gomar, J. Ciurana, and C. A. Rodríguez, "Analyzing effects of cooling and lubrication conditions in micromilling of Ti6Al4V," J. Clean. Prod., vol. 87, pp. 906-913, 2015.

[10] N. Banerjee and A. Sharma, "A comprehensive assessment of minimum quantity lubrication machining from quality, production, and sustainability perspectives," Sustain. Mater. Technol., vol. 17, p. e00070, 2018.

[11] R. Hood, J. Morris, and S. L. Soo, "Workpiece surface integrity when milling Udimet 720 superalloy," Procedia CIRP, vol. 45, pp. 283-286, 2016.

[12] M. Al, B. Mozammel, M. Nikhil, and R. Dhar, "Investigations on Surface Milling of Hardened AISI 4140 Steel with Pulse Jet MQL Applicator,” J. Inst. Eng. Ser. C, vol. 99, no. 3, pp. 301-314, 2018.

[13] G. D. P. Oliveira, M. C. Fonseca, and A. C. Araujo, "Analysis of residual stress and cutting force in end milling of Inconel 718 using conventional flood cooling and minimum quantity lubrication," pp. 3265-3272, 2017.

[14] N. Tosun and M. Huseyinoglu, "Effect of MQL on Surface Roughness in Milling of Effect of MQL on Surface Roughness in Milling of AA7075-T6," vol. 6914, 2010.

[15] S. B. Kedare, D. R. Borse, and P. T. Shahane, "Effect of Minimum Quantity Lubrication ( MQL ) on Surface Roughness of Mild Steel of 15HRC on Universal Milling Machine," MSPRO, vol. 6, no. Icmpc, pp. 150-153, 2014.

[16] K. Li and S. Chou, "Journal of Materials Processing Technology Experimental evaluation of minimum quantity lubrication in near micro-milling," J. Mater. Process. Tech., vol. 210, no. 15, pp. 2163-2170, 2010.

[17] A. Uysal, F. Demiren, and E. Altan, "Applying Minimum Quantity Lubrication (MQL) Method on Milling of Martensitic Stainless Steel by Using Nano Mos2 Reinforced Vegetable Cutting Fluid," Procedia - Soc. Behav. Sci., vol. 195, pp. 2742$2747,2015$.

[18] H. Hegab, B. Darras, and H. A. Kishawy, "Sustainability Assessment of Machining with Nano-Cutting Fluids," Procedia Manuf., vol. 26, pp. 245-254, 2018.

[19] T. Lv, S. Huang, X. Hu, Y. Ma, and X. Xu, "Tribological and machining characteristics of a minimum quantity lubrication ( MQL ) technology using GO / SiO 2 hybrid nanoparticle water-based lubricants as cutting fluids," pp. 2931-2942, 2018.

[20] P. Stief, J. Dantan, A. Etienne, and A. Siadat, "ScienceDirect ScienceDirect ScienceDirect Hybrid cooling and lubricating technology for CNC milling of Hybrid cooling and lubricating technology for CNC France milling of Inconel 718 nickel alloy Inconel 718 nickel alloy A new methodology to analyze funct," Procedia CIRP, vol. 77, no. Hpc, pp. 215-218, 2018.

[21] K. H. Park, M. A. Suhaimi, G. D. Yang, D. Y. Lee, S. W. Lee, and P. Kwon, "Milling of titanium alloy with cryogenic cooling and minimum quantity lubrication (MQL)," Int. J. Precis. Eng. Manuf., vol. 18, no. 1, pp. 5-14, 2017.

[22] M. Z. A. Yazid, G. A. Ibrahim, A. Y. M. Said, C. H. CheHaron, and J. A. Ghani, "Surface integrity of Inconel 718 when finish turning with PVD coated carbide tool under MQL," Procedia Eng., vol. 19, pp. 396-401, 2011.

[23] S. Kumar, D. Singh, and N. S. Kalsi, "Experimental Investigations of Surface Roughness of Inconel 718 under different Machining Conditions," Mater. Today Proc., vol. 4, no. 2, pp. 1179-1185, 2017.

[24] P. B. Patole and V. V. Kulkarni, "Optimization of Process Parameters based on Surface Roughness and Cutting Force in MQL Turning of AISI 4340 using Nano Fluid,” Mater. Today Proc., vol. 5, no. 1, pp. 104-112, 2018.

[25] R. K. Singh et al., "Influence of graphene-based nanofluid with minimum quantity lubrication on surface roughness and cutting temperature in turning operation," Mater. Today Proc., vol. 5, no. 11, pp. 24578-24586, 2018.

[26] S. H. Musavi, B. Davoodi, and S. A. Niknam, "Effects of reinforced nanoparticles with surfactant on surface quality and chip formation morphology in MQL-turning of superalloys," J. Manuf. Process., vol. 40, no. February, pp. 128-139, 2019.

[27] Y. Shuang, M. John, and D. Songlin, "Experimental investigation on the performance and mechanism of graphene oxide nanofluids in turning Ti-6Al-4V," J. Manuf. Process., vol. 43, no. May, pp. 164-174, 2019.

[28] P. B. Patole and V. V. Kulkarni, "Parametric Optimization of Minimum Quantity Lubrication in Turning of AISI 4340 Using Nano Fluids," Mater. Today Proc., vol. 5, no. 5, pp. 12419-12425, 2018.

[29] M. A. Mahadi, I. A. Choudhury, M. Azuddin, and Y. Nukman, "Use of Boric Acid Powder Aided Vegetable Oil Lubricant in Turning AISI 431 Steel,” Procedia Eng., vol. 184, pp. 128-136, 2017.

[30] Ç. V. Yıldırım, M. Sarıkaya, T. Kıvak, and Ş. Şirin, "The effect of addition of hBN nanoparticles to nanofluid-MQL on tool wear patterns, tool life, roughness and temperature in turning of Ni-based Inconel 625," Tribol. Int., vol. 134, no. February, pp. 443-456, 2019.

[31] A. Kumar Sharma, A. Kumar Tiwari, A. Rai Dixit, and R. Kumar Singh, "Measurement of machining forces and surface roughness in turning of AISI 304 steel using alumina-MWCNT hybrid nanoparticles enriched cutting fluid," Meas. J. Int. Meas. Confed., vol. 150, p. 107078, 2020.

[32] S. Niketh and G. L. Samuel, "Drilling performance of micro textured tools under dry, wet and MQL condition," J. Manuf. Process., vol. 32, pp. 254-268, 2018.

[33] E. A. Rahim and H. Sasahara, "A study of the effect of palm oil as MQL lubricant on high speed drilling of titanium alloys," Tribol. Int., vol. 44, no. 3, pp. 309-317, 2011.

[34] S. Werda, A. Duchosal, G. Le, A. Morandeau, and R. Leroy, "Minimum Quantity Lubrication : Influence of the oil nature on surface integrity," Procedia CIRP, vol. 45, pp. 287-290, 2016.

[35] N. Talib and E. A. Rahim, "Performance Evaluation of Chemically Modified Crude Jatropha Oil as a Bio-based Metalworking Fluids for Machining Process," Procedia CIRP, vol. 26, pp. 346-350, 2015.

[36] N. T. Mathew and L. Vijayaraghavan, "Environmentally friendly drilling of intermetallic titanium aluminide at different aspect ratio," J. Clean. Prod., vol. 141, pp. 439-452, 2017.

[37] B. De Agustina, F. Berzosa, E. M. Rubio, and M. M. Marín, "Experimental study of magnesium drilling based on the surface quality," Procedia CIRP, vol. 79, pp. 74-78, 2019. 
[38] A. Z. Sultan, S. Sharif, F. M. Nor, and D. Kurniawan, "Minimum quantity of lubricant drilling of stainless steel using refined palm olein: Effect of coating tool on surface roughness and tool wear," Procedia Manuf., vol. 30, pp. 427-434, 2019.

[39] S. Nandgaonkar, T. V. K. Gupta, and S. Joshi, "Effect of Water Oil Mist Spray (WOMS) Cooling on Drilling of Ti6Al4V Alloy Using Ester Oil Based Cutting Fluid," Procedia Manuf., vol. 6, pp. 71-79, 2016.

[40] R. Teimouri, S. Amini, M. Lotfi, and M. Alinaghian, "Sustainable drilling process of 1045 steel plates regarding minimum energy consumption and desired work quality," Int. J. Light. Mater. Manuf., vol. 2, pp. 397-406, 2019.

[41] J. S. Nam, P. H. Lee, and S. W. Lee, "Experimental characterization of micro-drilling process using nanofluid minimum quantity lubrication," Int. J. Mach. Tools Manuf., vol. 51, no. 7-8, pp. 649-652, 2011.

[42] S. S. Chatha, A. Pal, and T. Singh, "Performance evaluation of aluminium 6063 drilling under the influence of nanofluid minimum quantity lubrication," J. Clean. Prod., vol. 137, pp. 537-545, 2016.

[43] R. Rosnan, M. N. Murad, A. I. Azmi, and I. Shyha, "Effects of minimal quantity lubricants reinforced with nano-particles on the performance of carbide drills for drilling nickel-titanium alloys," Tribol. Int., vol. 136, no. November 2018, pp. 58-66, 2019.

[44] T. Tawakoli, M. J. Hadad, M. H. Sadeghi, A. Daneshi, S. Stöckert, and A. Rasifard, "An experimental investigation of the effects of workpiece and grinding parameters on minimum quantity lubrication-MQL grinding," Int. J. Mach. Tools Manuf., vol. 49, no. 12-13, pp. 924-932, 2009.

[45] F. Rabiei, A. R. Rahimi, M. J. Hadad, and M. Ashrafijou, "Performance improvement of minimum quantity lubrication (MQL) technique in surface grinding by modeling and optimization," J. Clean. Prod., vol. 86, pp. 447-460, 2015.

[46] L. M. Barczak, A. D. L. Batako, and M. N. Morgan, "A study of plane surface grinding under minimum quantity lubrication (MQL) conditions," Int. J. Mach. Tools Manuf., vol. 50, no. 11, pp. 977-985, 2010.

[47] M. Emami, M. H. Sadeghi, A. A. D. Sarhan, and F. Hasani, "Investigating the Minimum Quantity Lubrication in grinding of Al $2 \mathrm{O} 3$ engineering ceramic," J. Clean. Prod., vol. 66, pp. 632-643, 2014.

[48] M. Hadad, "An experimental investigation of the effects of machining parameters on environmentally friendly grinding process," J. Clean. Prod., vol. 108, pp. 217-231, 2015.

[49] H. Esmaeili, H. Adibi, and S. M. Rezaei, "An efficient strategy for grinding carbon fiber-reinforced silicon carbide composite using minimum quantity lubricant," Ceram. Int., vol. 45, no. 8, pp. 10852-10864, 2019.

[50] X. Zhang et al., "Lubricating property of MQL grinding of A12O3/SiC mixed nanofluid with different particle sizes and microtopography analysis by cross-correlation," Precis. Eng., vol. 47, pp. 532-545, 2017.

[51] Y. Zhang et al., "Experimental study on the effect of nanoparticle concentration on the lubricating property of nanofluids for MQL grinding of Ni-based alloy," J. Mater. Process. Technol., vol. 232, pp. 100-115, 2016.

[52] Y. Wang et al., "Experimental evaluation of the lubrication properties of the wheel/workpiece interface in MQL grinding with different nanofluids," Tribol. Int., vol. 99, pp. 198-210, 2016.

[53] M. Li et al., "Experimental evaluation of an eco-friendly grinding process combining minimum quantity lubrication and graphene-enhanced plant-oil-based cutting fluid," J. Clean. Prod., vol. 244, p. 118747, 2019. 